\title{
Optimal Utilitarian Taxation and Horizontal Equity*
}

\author{
Henrik Jordahl $^{\dagger}$ (YE) (presenter) and Luca Micheletto ${ }^{\ddagger}$ \\ Uppsala University and L. Bocconi University, Milan
}

January 18, 2002

\begin{abstract}
A bstract
We impose a horizontal equity constraint on the problem of finding the optimal utilitarian tax mix. The horizontal equity constraint requires that individuals with the same ability have to pay the same amount of taxes regardless of their preferences for leisure. Contrary to normal findings, we find that a good that is complementary to leisure need not be discouraged by the tax system, and that a good that normally should be discouraged by the tax system need not be taxed at a positive rate even if the economy is composed of only two private commodities plus leisure. Similarly, the marginal effective tax rate need not be equal to zero at the top when the tax mix obeys the horizontal equity constraint.
\end{abstract}

JEL-Classification: D63, H21, H24.

Keywords: Horizontal Equity, Optimal Taxation, Heterogenous Preferences, Utilitarianism.

\footnotetext{
${ }^{*}$ We thank Sören Blomquist, Umberto Galmarini, Agnar Sandmo, David Strömberg and seminar participants at Uppsala University and at the Nordic Workshop on Tax Policy and Public Economics in Uppsala 2001 for helpful comments and suggestions. Henrik Jordahl gratefully acknowledges financial support from the Jan Wallander och Tom Hedelius' foundation.

${ }^{\dagger}$ E-mail: henrik.jordahl@nek.uu.se.

${ }^{\ddagger}$ E-mail: luca.micheletto@uni-bocconi.it.
} 


\section{Introduction}

A well-known problem with income taxes is that they punish hard-working people. Nozick (1974), for example, asks why somebody who prefers looking at a sunset should get away with paying less taxes than somebody who has to earn money in order to attain his pleasures. This question is not only important on its own normative ground, but also because tax systems that blatantly violate general conceptions of equity risk being replaced if enough citizens call them into question.

As a matter of fact, such questions of equity have to a large extent been neglected in the optimal taxation literature, where one of the standard assumptions is that all individuals have the same preferences ${ }^{1}$. At the same time, a strand of the social choice literature has begun to study redistributive schemes where individuals must bear the consequences of certain inequalities. ${ }^{2}$ In particular, it is often advocated that an individual ought to bear the consequences of the characteristics which he has chosen himself. This line of reasoning is especially relevant for optimal income taxation if the utility of leisure is heterogeneous across individuals. In that case, the government may not want to compensate people for income differences that are due to differences in tastes. However, since it is generally assumed that the government can only observe an individual's income - neither his ability nor his supply of labour - it is impossible to find an income tax scheme that only compensates for differences in abilities. Indeed, in the public debate it is frequently pointed out that transfers to hard-working low-skilled persons are also benefiting more highly skilled but also more epicurean individuals, since the identity of individuals from these two types can hardly be distinguished by their (similar) pre-tax incomes. In this paper we investigate if and how the government can use linear commodity taxes in addition to nonlinear income taxation in order to escape this dilemma. Thus we consider the tax instruments typically observed in developed economies.

Related to the principle of responsibility for certain inequalities is the horizontal equity principle of equal treatment of equals. Indeed, an interpretation of the horizontal equity principle is that if two individuals differ

\footnotetext{
${ }^{1}$ Possible exceptions are provided by Cuff (2000) and Boadway et al. (2002) for the finite case, while Tarkiainen and Tuomala (1999) develop a computational approach to tackle the problem of two-dimensional population in the continuum case. All the quoted authors neglect the problem of the optimal structure of commodity taxation and work with models where leisure is additive separable from other consumption goods. Sandmo (1993) examines the utilitarian case for a linear income tax under the assumption that differences in earnings are explained by differences in preferences over work and consumption; he also has a brief section in which both market abilities and preferences for leisure are allowed to vary. Ebert (1988) provides conditions on the preference orderings and the utility functions which allow to transform the problem of optimal (utilitarian) income taxation for a two-dimensional population into a one-dimensional problem.

${ }^{2}$ See e.g. Fleurbaey and Maniquet (1999).
} 
only in tastes, then the government ought to treat them identically. The literature contains several suggestions of the status and definition of horizontal equity ${ }^{3}$. Musgrave (1959) argues that in the ability-to-pay approach to taxation, "horizontal and vertical equity are but different sides of the same coin." However, there are several reasons for taxing people with the same ability differently. Besides the conflicts arising from the government's lack of information, Stiglitz (1982) demonstrates that the horizontal equity requirement does not follow from the maximization of a traditional utilitarian or more general social welfare function (which does not consider relations between individual outcomes), and, more strongly, that it may also be inconsistent with Pareto optimality. In a recent contribution, Kaplow and Shavell (2001b) prove formally that any non-welfarist method of policy assessment ${ }^{4}$, such as the ones involved in the concern for horizontal equity, violates the Pareto principle.

In view of this expected conflict between horizontal and vertical equity, it is often argued that the former should take precedence over the latter. In line with this, Atkinson and Stiglitz $(1976,1980)$ suggest the imposition of a horizontal equity constraint on the maximization of a social welfare function $^{5}$. Feldstein (1976) instead suggests to balance the fulfilment of horizontal equity against the utilitarian principle of welfare maximization. Regarding the definition of horizontal equity, the proposed measures are as a rule either based on tax payments or on utilities. Still Johnson and Mayer (1962) emphasize the number of inequities, though this measure could be weighted by the corresponding differences in tax payments. Atkinson and Stiglitz $(1976,1980)$ refer to Pigou, who observed that persons with different tastes who pay the same amount of taxes will not necessarily suffer equal burdens in terms of foregone utility. Thus they argue that commodity taxes

\footnotetext{
${ }^{3}$ The relevance of this concept has recently been questioned in a series of articles by Kaplow (1989, 1995, 2000) and Kaplow and Shavell (2000, 2001a), where it is claimed that usually provided indices of deviations from horizontal equity are developed without knowing what they should try to measure and why, but merely stipulated or supported by ad hoc appeals to intuition. Moreover, Kaplow refers to and seems to share Westen's (1982) view, according to which "Equality will cease to mistify — and cease to skew moral and political discourse - when people come to realize that it is an empty form having no substantive content of its own. (...) The endurance of the principle of equalitythat likes should be treated alike - is due to the fact that it is empty of content. For the principle to have meaning, it must incorporate some external values, but once these external values are found, the principle of equality is superfluous." According to these authors, to pay attention to the unequal treatment of equals can be useful at most from a practical perspective. Even though the measures offered by horizontal equity indices are not of independent normative significance, in order to alert about circumstances in which something is amiss and social welfare, as the notion is conventionally understood, is reduced.

${ }^{4}$ The term "non-welfarist" refers to any conception of social welfare that gives weight to factors other than the satisfaction of the individuals' preferences.

${ }^{5}$ Actually, as recognized by Kaplow (1989), this approach helps avoiding at least some of the objections related to the concept of horizontal equity.
} 
should be set to maintain the parity of utilities for persons who, according to the government's value judgments, attained equal utility before the imposition of taxes. Feldstein (1976) on his part proposes measures based on actual utilities as experienced by the individuals. His measures include the after-tax variance of utilities for people who attained equal utilities before taxes were levied. Plotnick (1981) compares "preordered" and standard Lorenz curves and derives an index which is sensitive to the magnitude of the changes in income rankings produced by redistribution. Auerbach and Hassett (1999) propose a new income-based measure, suitable for applied work. Their idea is to incorporate horizontal equity in a social welfare function by weighting each inequity between two groups by the distance (e.g. in before-tax income) between these groups in a way that has been used in the econometric literature on kernel density functions. Other articulations of the concept of horizontal equity include Rosen (1978), King (1983), Berliant and Strauss (1985), and Balcer and Sadka (1986).

In this paper we stay close in spirit to the interpretation of the concept given by Bossert (1995) in terms of "equal transfers for equal circumstances" 6 , and require that agents belonging to the same ability type must pay the same amount of taxes irrespective of their preferences. This can be justified on the basis of the observation that people belonging to the same ability type share the same opportunity set, and while differences in this set can in some moral sense be deemed "irrelevant" and therefore call for compensation, differences in preferences may be regarded as morally "relevant", suggesting that compensation is ruled out for such differences. The consequence of this reasoning is that individuals are fully responsible for the structure of their preferences.

Our approach is to introduce the principle of equal transfers for equal circumstances as a constraint on the maximization of a utilitarian social welfare function. Although we have to admit that the choice of a tax-based rather than a utility-based measure is to some extent arbitrary, it is simple and also sufficient for focusing on the moral difficulties raised by the fact that the government can only observe income differences and not differences in abilities or preferences.

We find that the imposition of the horizontal equity requirement modifies the rule for optimal commodity taxes. Contrary to normal findings a good that is complementary to leisure need not necessarily be discouraged by the tax system, and perhaps more peculiar, a good that should be discouraged by the tax system in the absence of the horizontal equity condition need not necessarily be taxed at a positive rate once this condition is imposed, even if the economy is composed by only two private commodities plus

\footnotetext{
${ }^{6}$ This terminology comes from the division of the sources of individual outcomes into wills, resources and circumstances. According to this division, the individual is responsible for his wills, whereas the circumstances are factors outside his control. Differences in circumstances can be compensated by reallocating the resources.
} 
leisure $^{7}$. In essence, the trade-off between the effects on revenue from the commodity tax and the desire to encourage individuals to reveal their true characteristics (i.e. abstain from mimicking) is amended by the requirement to uphold horizontal equity. When this requirement is taken into account, the popular prescription to loosen the incentive compatibility constraint by taxing goods that are complementary to leisure more heavily, is only one part of the story. We also derive effective marginal tax rates for individuals with different characteristics and compare them with the tax rates derived in ordinary optimal taxation models. Also in this case we find that ordinary prescriptions have to be amended in order to satisfy the horizontal equity principle; particularly interesting, the popular "no distortion at the top (of the skill distribution)" result can be violated.

\section{The M odel}

In our model economy there are three goods (two private consumption goods $c$ and $z$ plus leisure), and three types of agents. Agents are characterized by their skill or ability $\left(w^{H}\right.$ or $\left.w^{L}\right)$ (reflected, by assumption of perfect competition, in the unitary wage rate they are paid) and by their taste for leisure $\left(\alpha^{H}\right.$ or $\left.\alpha^{L}\right)$, where superscript $H(L)$ denotes a high (low) ability or taste for leisure. There are $\pi^{1}$ low skilled, low taste for leisure agents (type 1 with $w^{L}$ and $\alpha^{L}$ ), $\pi^{2}$ high skilled, high taste for leisure agents (type 2 with $w^{H}$ and $\alpha^{H}$ ), and $\pi^{3}$ high skilled, low taste for leisure agents (type 3 with $w^{H}$ and $\left.\alpha^{L}\right)$. Preferences are represented by the utility function $u c, z, \alpha^{i} l$, where $\alpha^{i}$ is the particular preference parameter of an individual of type $i$ and $l$ is the supply of labour.

Production is linear and uses labour as the only input; units are chosen to make all producer prices equal to one, good $z$ is chosen as numéraire and is set untaxed, so that consumer prices are represented by the vector $(1+t, 1)=(q, 1)$. In addition to the commodity tax, $t$, the agents also have to pay a non-linear tax $T(Y)$ on income $Y$. Thus disposable income $B$ equals $Y-T(Y)$ and the total tax liability amounts to $\tau(Y) \rightrightarrows T(Y)+t c$. By using the relation $\frac{Y}{w}=l$, the indirect utility of type $i$ is $V^{i} \quad q, B^{i}, \frac{\alpha^{i}}{w^{i}} Y^{i}$, where the super index on the indirect utility function is for notational convenience only (all types share the same utility function). Henceforth ${ }^{\frac{\alpha}{w}}{ }_{(i)}$ will denote the ratio of the preference parameter to the productivity parameter for the representative agent of type $i$. The indirect utility function has the following self-evident properties: $V_{q}<0, V_{B}>0, V_{3}<0$ (the sub indices denote partial derivatives; in particular, $V_{3}$ denotes the partial derivative

\footnotetext{
${ }^{7}$ It is easy to show that in the standard optimal taxation problem with two private commodities plus leisure, where the indirect tax structure collapses to the definition of only one commodity tax rate, the concept of discouragement (encouragement) becomes the same as "being taxed at a positive rate" ("being subsidized").
} 
with respect to the third argument). In order to satisfy the single-crossing condition (indifference curves cross only once), we will also assume $V_{33}<0$ (labour is annoying at increasing rates) and $V_{B 3}<0$ (an increase in private consumption is valued more, the less "experienced hours" $(\alpha l)$ the person is working, i.e. normality of private consumption and "experienced" leisure).

To establish that single crossing holds, we will calculate the slopes of the indifference curves in (pre-tax income, disposable income)-space, henceforth referred to as $(Y, B)$-space, of the three types. The slope of such an indifference curve is given by

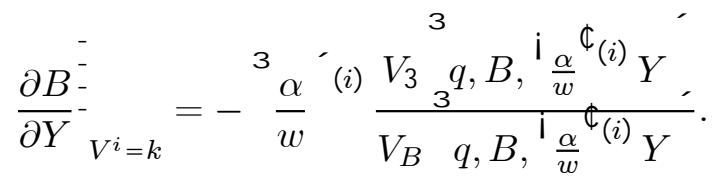

It turns out that the slopes of the three types indifference curves can be ranked according to the ratio of the preference parameter $\alpha$ to ability $w$. Comparing two types $i$ and $j$, the slope of the indifference curves of type $i$ are steeper than those of type $j$ if

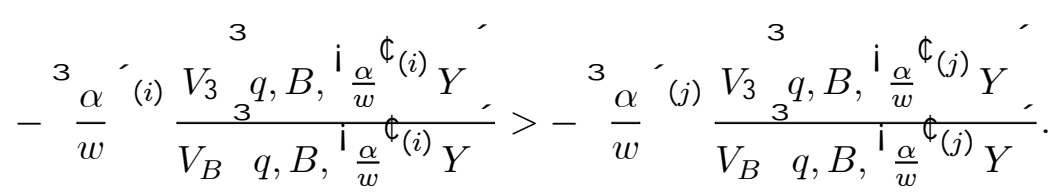

With the assumptions $V_{33}<0$ and $V_{B 3}<0$, this inequality is satisfied if $\mathbf{i}_{\frac{\alpha}{w}}{ }^{\mathcal{C}_{(i)}}>{ }^{\mathbf{i}_{\frac{\alpha}{w}}}{ }^{\boldsymbol{C}_{(j)}}$. Since, at every $(Y, B)$-bundle, the type specific ratio $\frac{\alpha}{w}$ determines the slope of the indifference curve for each type of agent, the indifference curves of two agents of different types can cross only once.

\subsection{A Comparison with R elated Models}

Compared with the related models developed by Cuff (2000) and Boadway et al. (2002), the distinguishing feature of our model is the introduction of an additional, taxable commodity. Cuff uses a model with three types of agents and a two goods economy (private consumption plus leisure), where high skilled agents have low taste for leisure, while there are low skilled agents with both high and low taste for leisure. In order to make the results comparable to those of Besley and Coate (1995), she uses individual utility functions that are affine in consumption.

Boadway et al. (2002) instead use a model with four types of agents (and the same two goods economy), in which low skilled agents with low taste for leisure are observationally indiscernible from the new type of high skilled agents with high taste for leisure. The agents' utility functions are quasi-linear, but in their case affine in labour. More precisely, they assume 
$U=u(z)-\alpha^{i} l$, and $\frac{\alpha^{L}}{w^{L}}=\frac{\alpha^{H}}{w^{H}}$. Thus the "intermediate" types are indistinguishable because they share the same map of indifference curves in $(Y, B)$-space.

Dealing with a two goods model, the quoted papers are confined to studying the shape of the optimal income tax schedule and cannot examine the potential role of commodity taxation. Notice however that, if $\frac{\alpha^{L}}{w^{L}}=$ $\frac{\alpha^{H}}{w^{H}}$, then, even in a multi-commodities framework where individual utility functions are not separable between leisure and other goods, commodity taxes could not be employed in order to screen between low skilled, low taste for leisure agents and high skilled, high taste for leisure ones.

Suppose now, as in our model, that we have an economy composed of three goods (two private consumption goods $c$ and $z$ plus leisure), where there are three types of individuals: type 1 with high ability and low taste for leisure, type 2 with high ability and high taste for leisure, and type 3 with high ability and low taste for leisure. Suppose also, as in Boadway et al. (2002), that type 1 and type 2 are indiscernible because $\frac{\alpha^{L}}{w^{L}}=\frac{\alpha^{H}}{w^{H}}$, and that they share the same map of indifference curves in $(Y, B)$-space. Finally, assume as we proposed in the introduction, that the concern for horizontal equity translates into the requirement that the total tax liability of agents of type 2 and type 3 must be the same, and that the social planner maximizes a utilitarian social welfare function subject to the self-selection constraints (stating that no agent would gain by masquerading as an agent of a different type) and the budget-balance constraint for the government. In this situation we can have two cases, depending on whether taxation is merely redistributive or if the government has an exogenous amount of expenditure to finance. In the former case the solution involves no taxation at all and the optimal outcome is the laissez-faire one. This is due to the fact that, since there is necessarily bunching ${ }^{8}$ between type 1 and type 2 , the horizontal equity requirement $\tau^{2}=\tau^{3}$ implies that we must have $\tau^{1}=$ $\tau^{2}=\tau^{3}$. Everybody must pay the same amount of taxes and, since there is no public expenditure to finance, no taxation is involved. In the latter case, suppose that the government has to collect a fixed positive amount of revenue. Following the same reasoning as before, we know that each type of agents must pay the same amount of taxes. Since income and commodity taxation are both distortive and cause a deadweight loss, the optimal policy is a uniform lump sum tax which involves no excess burden.

Boadway et al. (2002) are, as we mentioned above, concerned with the limit situation where high skilled individuals with a high taste for leisure

\footnotetext{
${ }^{8}$ According to Weymark (1986), bunching is said to occur if individuals with different characteristics receive the same commodity bundle. In fact as long as $\frac{\alpha^{L}}{w^{L}}=\frac{\alpha^{H}}{w^{H}}$, agents of type 1 and of type 2 will not only receive the same allocation in $(Y, B)$-space, but they will also spend their disposable income across goods in exactly the same way, and this is true even if preferences are not separable between leisure and other goods.
} 
cannot be distinguished from low skilled individuals with a low taste for leisure. In our paper, we relax this hypothesis and consider the assumption:

$$
\frac{\alpha^{L}}{w^{L}}<\frac{\alpha^{H}}{w^{H}} .
$$

This implies the following chain of inequalities:

$$
\frac{\alpha^{L}}{w^{H}}<\frac{\alpha^{L}}{w^{L}}<\frac{\alpha^{H}}{w^{H}}
$$

At every point in $(Y, B)$-space, the slope of the indifference curve of a low skilled, hard working agent is shallower than the one of a high skilled, epicurean agent, and for this pair of agents the ordinary ranking of the indifference curves based on their slopes is reversed. ${ }^{9}$

\subsection{Some Considerations about the Pattern of the Binding Self-selection Constraints}

In conventional hidden information optimal taxation models, the unobservability of the agents' types raises a familiar problem. The government may wish to redistribute resources from high skilled to low skilled types (since laissez faire utility normally increases with the wage rate). Not knowing who is who, however, all it can do is to tax higher incomes more heavily than lower incomes. This may create an incentive for a high skilled agent to reduce his labour supply in order to earn the same gross income as a low skilled agent. Thus, having imposed the single crossing condition, the binding self-selection constraint that thwarts the government in its attempts to redistribute among individuals runs downwards from high skilled (high earning) agents towards low skilled (low earning) ones. In a finite-class economy this is generalized by saying that an optimal allocation results in a simple monotonic chain to the left (Guesnerie and Seade, 1982), which means that each pair of successive bundles are L-linked ${ }^{10}$ by a downwards

\footnotetext{
${ }^{9}$ If we had instead made the assumption $\frac{\alpha^{H}}{w^{H}}<\frac{\alpha^{\mathrm{L}}}{w^{\mathrm{L}}}$, the chain of inequalities would have been the following:

$$
\frac{\alpha^{L}}{w^{H}}<\frac{\alpha^{H}}{w^{H}}<\frac{\alpha^{L}}{w^{L}}
$$

This case reflects more closely the standard one since there is no agent with high ability that has indifference curves in $(Y, B)$-space that are steeper than the ones of the low skilled agents. Since the reasoning is not changed fundamentally and the algebra becomes a bit more tedious when we make this alternative assumption, we will neglect the possibility of having $\frac{\alpha^{\mathrm{H}}}{w^{\mathrm{H}}}<\frac{\alpha^{\mathrm{L}}}{w^{\mathrm{L}}}$. The complete derivations of the optimal tax mix for this case is available upon request.

${ }^{10}$ Using the terminology of Guesnerie and Seade (1982), a corner (or chosen bundle) is linked to another if they both belong to the optimal set of some agent h; or equivalently if there is an indifference curve of $\mathrm{h}$ which passes through both corners and is the highest $\mathrm{h}$ can reach on the budget set. This agent $\mathrm{h}$ is said to link these corners. $\mathrm{A}$ corner $\mathrm{C}_{i}$ is
} 
binding incentive-compatibility constraint. However, as long as individuals differ both according to their market ability and according to their preferences for leisure, this is no longer necessarily true even if (as in our case) the single crossing condition still holds. Thus we cannot tell a priori which one of the pair of self-selection constraints connecting two types is going to be binding. Under certain circumstances, both constraints could even be binding at the same time (generating what Brito et al. (1990) call a "self-selection cycle"). Notice that the mentioned properties are a common feature of all models that introduce heterogeneity along more than one dimension (see Balestrino, Cigno and Pettini (1999) and Cremer, Pestieau and Rochet (2001)). Finally, notice also that although the single crossing condition holds in our model, it will not generally do so in models with more than one differentiating characteristic of the agents.

\section{The Optimal Tax M ix}

In this section we solve the model for the optimal tax mix under the assumption about the agents' indifference curves described in the previous section. Thus we assume $\frac{\alpha^{L}}{w^{H}}<\frac{\alpha^{L}}{w^{L}}<\frac{\alpha^{H}}{w^{H}}$. Horizontal equity requires that

$$
Y^{3}-B^{3}+t c^{3}=Y^{2}-B^{2}+t c^{2} \Longrightarrow Y^{3}=t^{i} c^{2}-c^{3^{\Phi}}+Y^{2}-B^{2}+B^{3}
$$

i.e. that total taxes paid by an agent of type 2 equal total taxes paid by an agent of type 3. By choosing a utilitarian objective, the planner's problem becomes:

$$
\begin{aligned}
& \max _{B^{1}, B^{2}, B^{3}, Y^{1}, Y^{2}, t} \pi^{1} V^{1} \stackrel{\mu}{q}, B^{1}, \frac{\alpha^{L}}{w^{L}} Y^{1} \text { ๆ } \pi^{2} V^{2} \stackrel{\mu}{\mu}, B^{2}, \frac{\alpha^{H}}{w^{H}} Y^{2}+ \\
& +\pi^{3} V^{3}{ }^{\mu} q, B^{3}, \frac{\alpha^{L}}{w^{H}} t^{\mathrm{f}} c^{2}-c^{3^{\Phi}}+Y^{2}-B^{2}+B^{3^{\mathbf{a}^{\mathbf{9}}}},
\end{aligned}
$$

subject to the budget constraint:

$\pi^{1}{ }^{\mathrm{i}} Y^{1}-B^{1}+t c^{1^{\phi}}+\pi^{2}{ }^{\mathrm{i}} Y^{2}-B^{2}+t c^{2^{\phi}}+\pi^{3^{\mathrm{i}}} Y^{2}-B^{2}+t c^{2^{\phi}} \geq G$

and the following self-selection constraints:

$V^{1}{ }^{\mu} q, B^{1}, \frac{\alpha^{L}}{w^{L}} Y^{1} \geq \forall^{\mu} \stackrel{\text { ी }}{\mu}, B^{2}, \frac{\alpha^{L}}{w^{L}} Y^{2}$,

W-linked (W for winner) if some $\mathrm{h}$ links $\mathrm{C}_{i}$ to some other corner $\mathrm{C}_{j}$, and is allocated $\mathrm{C}_{i}$. A corner $\mathrm{C}_{i}$ is L-linked ( $\mathrm{L}$ for loser) if some $\mathrm{h}$ links $\mathrm{C}_{i}$ to $\mathrm{C}_{j}$, and is allocated $\mathrm{C}_{j}$. 


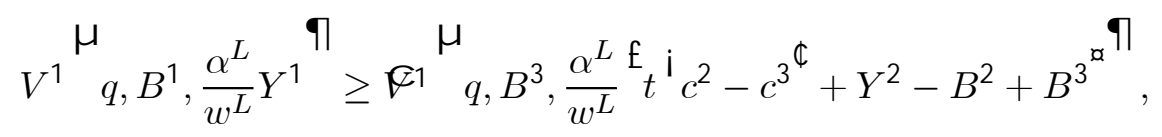

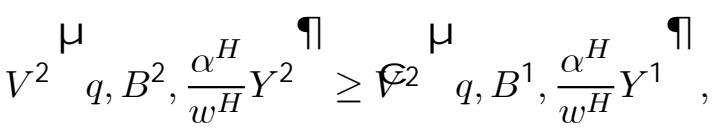

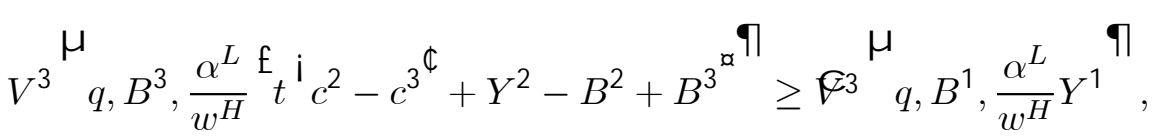

3 $\lambda_{3}^{d}$

where we have substituted the horizontal equity constraint into the indirect utility function of type 3 agents and a "hat" above the function $V^{i}$ indicates that the indirect utility is evaluated at a point where type $\mathrm{i}$ is mimicking another type. The sub indices on the Lagrange multipliers indicate the type of the potential mimicker, and the super indices indicate the direction of the incentive compatibility constraint: "u" for upwards and "d" for downwards (according to the ranking given by the slopes of the indifference curves). Since single crossing holds, we only need to take the self-selection constraints linking pairs of adjacent individuals into account. In accordance with standard practice in the optimal taxation literature, we will simply assume that a solution exists and characterize the optimal tax mix conditional on this assumption.

Moreover, the way we have chosen to incorporate the constraint (5) implies that every variation in $B^{2}, B^{3}, Y^{2}$ and $t$ must be accompanied by a proper variation in $Y^{3}$, the pre-tax income of type 3 agents, in order to match the horizontal equity requirement. By differentiating the horizontal equity constraint (5), and denoting with $c_{3}^{i}$ the derivative of the demand of agents of type $i$ for commodity $c$ with respect to the third argument in the individual utility function, we get the following useful results:

$$
\begin{gathered}
\frac{d Y^{3}}{d B^{2}}=\frac{t \frac{\partial c^{2}}{\partial B^{2}}-1}{1+t c_{3}^{3} \frac{\alpha^{L}}{w^{H}}} \\
\frac{d Y^{3}}{d B^{3}}=\frac{1-t \frac{\partial c^{3}}{\partial B^{3}}}{1+t c_{3}^{3} \frac{\alpha^{L}}{w^{H}}} \\
\frac{d Y^{3}}{d Y^{2}}=\frac{1+t c_{3}^{2} \frac{\alpha^{H}}{w^{H}}}{1+t c_{3}^{3} \frac{\alpha^{L}}{w^{H}}} \\
\frac{d Y^{3}}{d q}=\frac{c^{2}-c^{3}+t \frac{\partial c^{2}}{\partial q}-\frac{\partial c^{3}}{\partial q}}{1+t c_{3}^{3} \frac{\alpha^{L}}{w^{H}}}
\end{gathered}
$$




\section{The Commodity Tax Rate}

Next we will derive a formula for the commodity tax that maximizes the planner's objective above. The first order condition of this problem with respect to the commodity tax rate, $t$, is:

$$
\begin{aligned}
& \pi^{1} V_{q}^{1}+\pi^{2} V_{q}^{2}+\pi^{3} \quad V_{q}^{3}+V_{3}^{3} \frac{\alpha^{L}}{w^{H}} c^{2}-c^{3}+t \frac{\partial c^{2}}{\partial q}-\frac{\partial c^{3}}{\partial q} \frac{1}{1+t c_{3}^{3} \frac{\alpha^{L}}{w^{H}}}+ \\
& +\gamma \pi^{1} c^{1}+{ }^{\mathrm{i}} \pi^{2}+\pi^{3^{\natural}} c^{2}+t \frac{\mu c^{1}}{\partial q} \pi^{1}+\frac{\partial c^{2}}{\partial q} \pi^{2}+\pi^{3^{\boldsymbol{q}^{\natural}}}+
\end{aligned}
$$

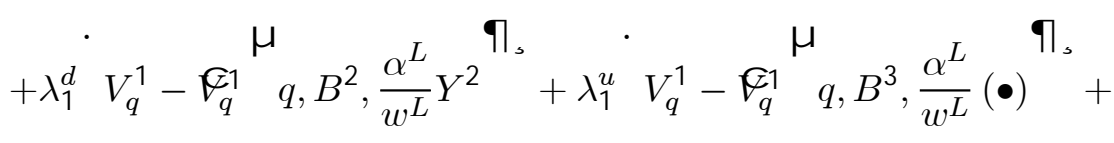

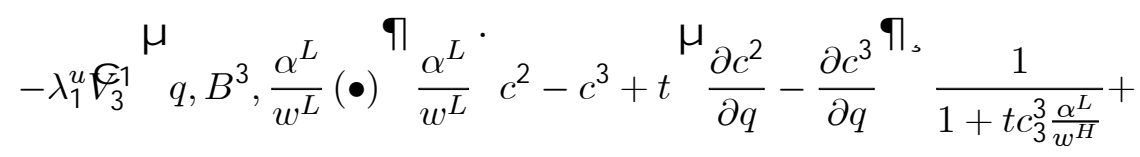

$$
\begin{aligned}
& +\lambda_{2}^{u} V_{q}^{2}-\nabla_{q}^{2}+\lambda_{1}^{d} V_{q}^{3}-\nabla_{q}^{3}+\lambda_{3}^{d} V_{3}^{3} \frac{\alpha^{L}}{w^{H}} c^{2}-c^{3}+t^{\mu} \frac{\partial c^{2}}{\partial q}-\frac{\partial c^{3}}{\partial q} \frac{1}{1+t c_{3}^{3} \frac{\alpha^{L}}{w^{H}}}=0 .
\end{aligned}
$$

If we consider the "normal" case when redistribution goes from high- to low-skilled agents we can invoke Proposition 1 by Brito et al. (1990) to show that $\lambda_{1}^{u}=\lambda_{1}^{d}=0$. The proposition states that, at any efficient allocation, agents of one type will always view the bundles of agents of other types that have a larger total tax liability as strictly inferior to their own. By applying Roy's identity, making use of the first order conditions for $B^{1}, B^{2}$ and $B^{3}$ and also the Slutsky equation (see Appendix A), eq. (11) can be written:

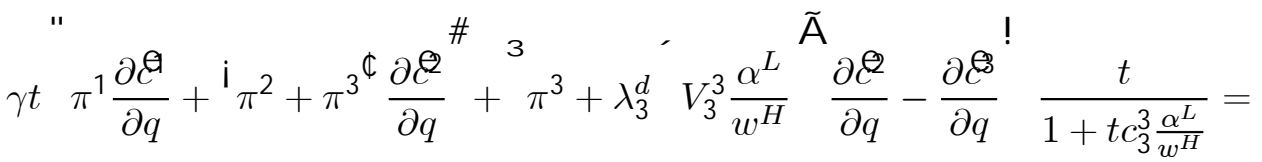

$$
\begin{aligned}
& =\lambda_{2}^{u} \Theta_{B}^{2} c^{1}-c^{2}+\lambda_{3}^{d} \Theta_{B}^{3} c^{1}-c^{B},
\end{aligned}
$$

where $\mathbf{e}$ denotes compensated demand.

Let's try to explain the difference between our formula and the structure one usually gets when defining the optimal commodity tax rule. In order to facilitate a comparison, we report the formula that we would have obtained if we hadn't introduced the additional constraint requiring horizontal equity: 


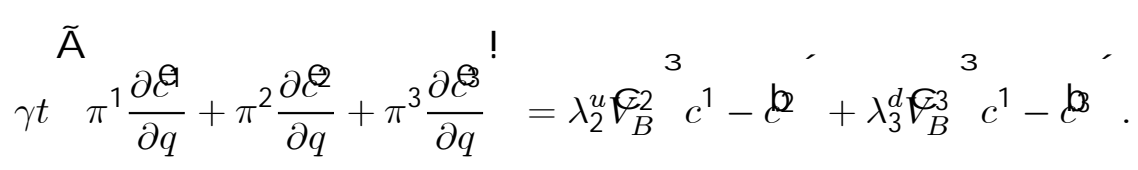

In particular, the only differences between eq. (12) and eq. (13) are found on the left-hand sides. The structure of the standard formula for optimal commodity taxation (in a framework where it supplements a non-linear income tax schedule) involves a trade-off between the gains in terms of weakening the self-selection constraints and the effects on government's revenue due to a marginal increase in one of the commodity tax rates. Moreover, the revenue effects are evaluated only indirectly through the change in the pattern of hicksian commodity demands since the marginal increase in the tax rate is performed in a compensated way. Having this in mind it becomes easy to interpret eq. (12). In fact, inside the square brackets, $\pi^{3} \frac{\partial \mathcal{\varepsilon}}{\partial q}$ replaces $\pi^{3} \frac{\partial \mathcal{\varepsilon}}{\partial q}$ since in the budget constraint, the variables referring to agents of type 3 are replaced by the condition requiring that the total tax liability of all the high skilled agents is the same. The second term on the left-hand side of eq. (12) measures the impact of the compensated increase in the commodity tax rate on the indirect utility of agents of type 3 . This impact is socially evaluated, i.e. weighted by the numerosity of type 3 agents, and the magnitude of the Lagrange multiplier of the constraint that prevents agents of this type from mimicking agents of type 1 . This impact differs from zero because we have imposed an additional constraint on the "classical" optimal tax problem, and the substitution of this constraint into the social objective function implies adjustments in the gross income (i.e. in labour supplied) of the high skilled, hard working agents to accommodate every variation in one of the variables entering the indirect utility function of high skilled, high taste for leisure agents.

However, this "intuitive" explanation needs to be proved formally and this is what we are going to do next. For this purpose, consider the effects of a small increase $d q$ in the tax rate on commodity $c$ accompanied by reductions $d T^{i}=-c^{i} d q<0, i=1,2,3$, in the income tax liabilities of the three types of agents at their original earnings. This reform has no effect on the welfare of either type one or two since by use of Roy's identity:

$d V^{i}=V_{q}^{i} d q+V_{B}^{i} d B^{i}=-V_{B}^{i}\left(c^{i} d q+d T^{i}\right)=-V_{B}^{i}{ }^{\mathbf{i}} c^{i}-c^{i^{\Phi}} d q=0, \quad i=1,2$.

Now look at the impact of this "compensated" reform on the welfare of the agents belonging to type three: this is measured by 


$$
\begin{aligned}
d V^{3}= & V_{q}^{3} d q+V_{B}^{3} d B^{3}+V_{3}^{3} \frac{\alpha^{L}}{w^{H}} c^{2}-c^{3}+t \frac{\partial c^{2}}{\partial q}-\frac{\partial c^{3}}{\partial q} \frac{1}{1+t c_{3}^{3} \frac{\alpha^{L}}{w^{H}}} d q+ \\
& +V_{3}^{3} \frac{\alpha^{L}}{w^{H}} \quad 1-t \frac{\partial c^{3}}{\partial B^{3}} \frac{1}{1+t c_{3}^{3} \frac{\alpha^{L}}{w^{H}}} d B^{3}+V_{3}^{3} \frac{\alpha^{L}}{w^{H}} t \frac{\partial c^{2}}{\partial B^{2}}-1 \frac{1}{1+t c_{3}^{3} \frac{\alpha^{L}}{w^{H}}} d B^{2} .
\end{aligned}
$$

Substituting $d B^{2}=c^{2} d q$ and $d B^{3}=c^{3} d q$ into the previous expression and making use of Roy's identity, one gets

$$
d V^{3}=V_{3}^{3}{\frac{\alpha^{L}}{w^{H}}}^{\cdot \mu} \frac{\partial c^{2}}{\partial q}-\frac{\partial c^{3}}{\partial q}+t c^{2} \frac{\partial c^{2}}{\partial B^{2}}-c^{3} \frac{\partial c^{3}}{\partial B^{3}} \frac{1}{1+t c_{3}^{3} \frac{\alpha^{L} w^{H}}{2}} d q
$$

which by use of the Slutsky equation can be written

$$
d V^{3}=V_{3}^{3} \frac{\alpha^{L}}{w^{H}} \quad \frac{\partial e^{\Theta}}{\partial q}-\frac{\partial e^{\Theta}}{\partial q} \frac{t}{1+t c_{3}^{3} \frac{\alpha^{L}}{w^{H}}} d q
$$

We can refer to (17) as to the non-sterilized (due to the necessity to match the horizontal equity constraint) effect on utility of a compensated (in the standard meaning of the term) increase in the commodity tax rate. Eq. (12) can therefore be written as

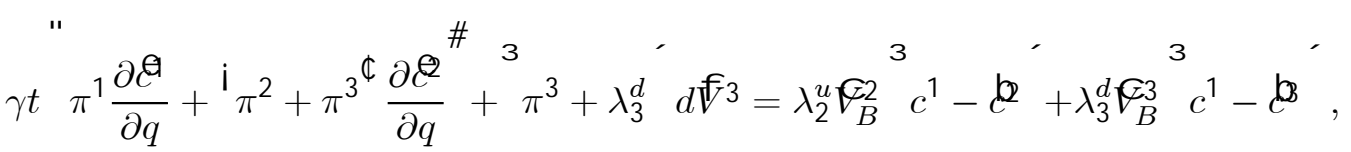

where $d V^{3}$ is equal to the quantity $\frac{d V^{3}}{d q}$ in eq. (17) and the "tilde" helps to remember that this effect is produced by a "compensated" marginal variation in the commodity tax rate.

In order to clarify the mechanisms of our model, it is instructive to check the sign of $d \mathfrak{V}^{3}$. It is easy to recognize that, since $V_{3}^{3}$ is negative, the "compensated" effect of the conjectured reform on the indirect utility of agents of type 3 is positive if and only if $\frac{\partial \mathcal{E}}{\partial q}-\frac{\partial \mathcal{E}}{\partial q} \frac{t}{1+t c_{3}^{3} \frac{\alpha^{L}}{w^{H}}}<0$; in turn, this requirement means that one of the four following conditions holds:
i) $\quad t>0$,

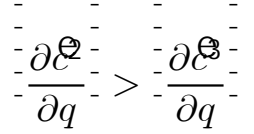
and $\quad 1+t c_{3}^{3} \frac{\alpha^{L}}{w^{H}}>0$
ii) $\quad t>0$,

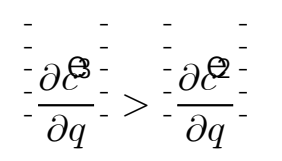$$
\text { and } \quad 1+t c_{3}^{3} \frac{\alpha^{L}}{w^{H}}<0
$$ 
iii)

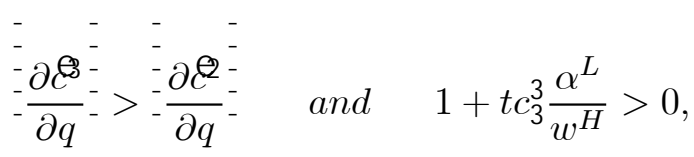

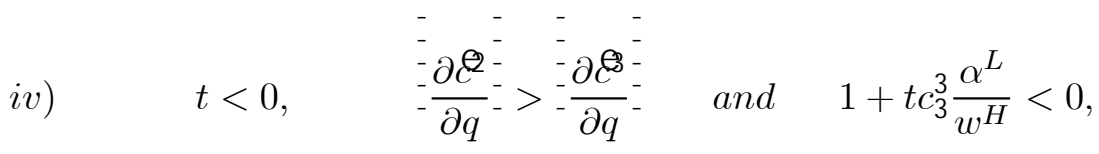

(where $|\bullet|$ denotes absolute values).

Regarding the conditions that make $d f^{3}<0$, we only give the one which will turn out to be useful later on:

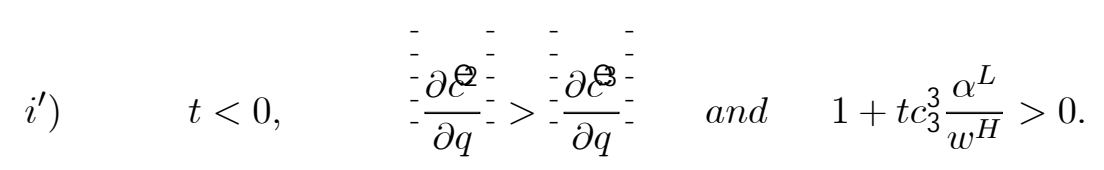

Conditions $i$ ) and iii) are characterized by the quite reasonable assumption that $1+t c_{3}^{3} \frac{\alpha^{L}}{w^{H}}$ is bigger than zero, and denote situations starting from which a marginal increase in the commodity tax rate (or reduction in the commodity subsidy rate) raises the total tax liability of an agent of type 3 (high skilled, low taste for leisure) more than the one of an agent of type 2 (high skilled, high taste for leisure). This in turn means that there is a need to reduce the total tax liability of the former agent and this objective is (as intuition would suggest) achieved by means of a (utility enhancing) reduction in his income tax liability (i.e. gross income $Y^{3}$ ).

Conditions $i i)$ and $i v$ ) instead characterize situations where a marginal increase in the commodity tax rate (or reduction in the commodity subsidy rate) weighs upon agents of type 3 less than it does upon agents of type 2 since relatively more revenue is extracted from the latter type of agents. This in turn means that in order to match the horizontal equity constraint it is necessary to raise the total tax liability of the former type of agents. However, in this case the goal is achieved, counterintuitively, via a reduction in the gross income $Y^{3}$. Since in this case $1+t c_{3}^{3} \frac{\alpha^{L}}{w^{H}}<0$, the net effect of a marginal increase $Y^{3}$ on the government's revenue is negative even if the marginal unit of income is taxed at a 100 percent rate. This is due to the recomposing of demand across consumption goods which greatly reduces indirect tax receipts. To raise the total tax payment of agents of type 3 , one has to lower their gross income and rely on the positive net effect working through the change in the consumption pattern.

However, conditions $i i$ ) and $i v$ ) are mainly a curiosity, and can never hold at an interior optimum; actually, it can be proved that they turn out to be conflicting with one of the first order conditions of the planner's problem. To show this, take the derivative of the budget constraint of an agent of type $3\left(q c^{3}+z^{3}=B^{3}\right)$ with respect to disposable income, $B$ : 


$$
q c_{B}^{3}+z_{B}^{3}=1 \Longrightarrow 1-t c_{B}^{3}=c_{B}^{3}+z_{B}^{3} .
$$

If commodities $c$ and $z$ are normal, from (19) we have $1-t c_{B}^{3}>0$. A necessary requirement for eq. (A7) in Appendix $\mathrm{A}$ to be satisfied is that $\frac{1-t c_{B}^{3}}{1+t c_{3}^{3} \frac{\alpha^{L}}{w^{H}}}=\frac{d Y^{3}}{d B^{3}}>0\left(\right.$ since $V_{B}^{3}>0$ and $\left.V_{3}^{3}<0\right)$ but, if $1-t c_{B}^{3}>0$, then this is only compatible with $1+t c_{3}^{3} \frac{\alpha^{L}}{w^{H}}>0$.

We should also notice a particular consequence of the assumption $\frac{\alpha^{L}}{w^{L}}<$ $\frac{\alpha^{H}}{w^{H}}$. Under this assumption agents of type 2 have the steepest indifference curves in $(Y, B)$-space even though they actually are high skilled and receive a high wage per hour, because their preferences involve a high taste for leisure. This in turn entails that the two terms on the right-hand side of eq. (12) must have opposite signs (or both be equal to zero) although the two mimickers are both high skilled agents and, to mimic the bundle intended for agents of type 1, they provide the same quantity of effective labour, smaller than that provided by the mimicked agents. In fact, notice that demand for commodity $c$ can be expressed as $c=c(q, B, \alpha l)$; taking the derivative with respect to labour, we have that the consumption of the taxed commodity is positively related to labour (leisure) if $\alpha c_{3}>(<) 0$ (which means if $c_{3}>(<) 0$ ). As mimickers, both agents of type 2 and agents of type 3 will earn the same pre-tax income $Y^{1}$ as agents of type one; therefore the following chain of inequalities holds:

$$
\frac{\alpha^{H}}{w^{H}} Y^{1}>\frac{\alpha^{L}}{w^{L}} Y^{1}>\frac{\alpha^{L}}{w^{H}} Y^{1}
$$

which implies

$$
\alpha^{H} \mathbf{p}>\alpha^{L} l^{1}>\alpha^{L} \mathbf{p},
$$

where $\mathbf{p}=\boldsymbol{k}=\boldsymbol{b}$ denote the common (since agents of type 2 and agents of type 3 are both high skilled agents and are paid the same wage rate $w^{H}$ ) level of labour supplied by agents of type 2 and agents of type 3 in order to mimic agents of type 1 . Under assumption $1, c_{3} \neq 0$ is therefore a sufficient condition to ensure that a true low skilled agent's consumption of the taxed good is in between the consumption of this good chosen by a high skilled, hard working mimicker andзa high skilled, epicurean mimicker, which means that sign $c^{1}-c^{\mathbf{Q}} \neq \operatorname{sign} \quad c^{1}-c^{\mathrm{B}}$.

Having interpreted eq. (12), the rule for the optimal commodity tax, and also having clarified some of the details of this rule, we are ready to state its novel properties in a proposition. Following the proposition, we will discuss the intuition behind some of the most interesting cases.

Proposition 1 At the constrained utilitarian optimum (with redistribution from high to low skilled agents) under the assumption $\frac{\alpha^{L}}{w^{L}}<\frac{\alpha^{H}}{w^{H}}$ in our two 
goods model, it is not always true that:

(a) a commodity that is complementary to leisure should be discouraged whereas a commodity that is complementary to labour should be encouraged; (b) a commodity that is normally expected to be encouraged should be subsidized whereas a commodity that is normally expected to be discouraged should be taxed at a positive rate.

\section{Proof. See Appendix B.}

Proposition 1 clearly differs from the popular prescription in the literature on optimal taxation telling that goods complementary to labour should be encouraged while goods complementary to leisure ${ }^{11}$ should be discouraged by the commodity tax system (whereas "encouraged" and "discouraged" are both intended in the Mirrleesian sense ${ }^{12}$ ). In the standard ${ }^{13}$ counterpart of eq. (13) with many types of agents and many commodities, this is reflected in that the expression on the right-hand side, which provides a social evaluation of the gains in terms of relaxing the binding incentive compatibility constraints arising from a marginal (compensated) increase in one of the commodity tax rates, is positive (negative) if the commodity which price is marginally increased by the tax is complementary to labour (leisure).

We have already observed that, when people differ along more than one dimension, we cannot invoke Proposition 6 by Guesnerie and Seade (1982), and say that the budget set will be a simple monotonic chain to the left. In our model, the horizontal equity constraint together with the assumption of redistribution from high- towards low skilled agents (what we referred to as the "normal" case) imply that the direction of mimicking "converges to the centre", which, using Guesnerie and Seade terminology, means that the corner intended for the low skilled agents is L-linked (see footnote 10) to both of the corners intended for the two different types of high skilled agents. This remark explains why it is not necessarily expected that a commodity complementary to labour should be encouraged or a commodity complementary to leisure should be discouraged by the indirect tax system.

The feature just mentioned is shared by all models where the Paretoefficient tax structure doesn't entail a simple monotonic chain to the left,

\footnotetext{
${ }^{11}$ Complementary to labour (leisure) is here used as a short for and corresponds to the definition by Pollak (1969) of negatively related to leisure (labour).

${ }^{12}$ In a general context where there are $n$ commodities and $m$ agents, the index of discpuragement of commodity $i$ is defined by Mirrlees (1976) as $d_{i}=\prod_{h=1 j=1}^{P_{h}} P_{2} \frac{\partial x_{i}^{f_{h}}}{\partial q_{j}} t_{j}{ }_{h=1}^{P_{h}} x_{i}^{h}$, where $q$ and $t$ denote respectively consumer prices and commodity tax rates, $x_{i}^{h}$ is the demand for commodity $i$ by agent $h$ and a tilde denotes hicksian demand. The index is an approximate measure of the change in compensated demand due to the tax system; positive values of the index mean that the commodity is encouraged by the indirect tax system, while negative values correspond to discouragement.

${ }^{13}$ Standard is here meant to describe a situation where individuals differ only with regard to their skill level and wages are exogenous.
} 
but in our model a second peculiarity stands out which is strictly related to the introduction of the horizontal equity constraint. In particular, whereas in the standard model with two private consumption goods, the term by which the commodity tax rate $t$ is multiplied is always negative (because of the concavity of the expenditure function), here it is not possible to rule out the circumstance that, due to the presence of an additional factor $\left(d \mathbf{f}^{3}\right)$, the aforesaid term turns out to be positive, in which case we should have the "anomalous" prescriptions that a commodity to be encouraged, according to the sign of the right-hand side of eq. (12), should in fact be taxed at a positive rate, whereas a commodity to be discouraged, always according to the sign of the right-hand side of eq. (12), should actually be subsidized.

Thus, a commodity that is complementary to labour and that also should be encouraged according to the right-hand side of eq. (12) can nonetheless be taxed at a positive rate. Starting with a positive value of the commodity tax rate, we have that even if a decrease in the excise would be beneficial in terms of (compensated) revenue and weakening of the self-selection constraints, this policy measure is not implemented because the benefits are more than offset by the high cost in terms of reduction of the indirect utility of agents of type 3 descending from the demand to keep the horizontal equity constraint satisfied, which would require an increase in the gross income $Y^{3}$ (cf. condition i)). Similarly, a commodity that is complementary to leisure and that also should be discouraged according to the right-hand side of eq. (12) can nevertheless be subsidized. Starting with a negative value of the commodity tax rate, even if an increase in the excise would be beneficial in terms of (compensated) revenue and weakening of the self-selection constraints, this policy measure does not take place because of the damaging effect on the indirect utility of agents of type three coming from the increase in the gross income $Y^{3}$ needed to maintain the horizontal equity constraint satisfied (cf. condition $\mathrm{i}^{\prime}$ ).

\section{The Marginal Effective Tax Rates}

We turn now to the problem of the evaluation of the marginal effective tax rate (METR) faced by the agents at the optimal allocation. We will derive an expression for the METR, characterize the METR in a proposition, and briefly discuss the (rather standard) results at the end.

Since in this model there are only two commodities and one of them is chosen as numéraire and set untaxed, the effective tax rate is defined as

$$
\tau(Y)=T(Y)+t c \quad q, Y-T(Y), \frac{\alpha}{w} Y^{\mathbf{i}}
$$

where $T(Y)=Y-B$ represents the income tax liability. By differentiation of $(20)$ we get the marginal effective tax rate 


$$
\tau^{\prime}=T^{\prime}+t \frac{\partial c}{\partial B} \mathbf{i} 1-T^{\prime}{ }^{\Phi}+c_{3} \frac{\alpha^{\lrcorner}}{w}
$$

As usual we can derive an expression for the marginal income tax rate faced by an agent by considering his optimal choice of ląbour supply. The first order conditions of the problem $\max V^{1} q, B, \frac{\alpha}{w} Y^{4}$ subject to $B=$ $Y-T(Y)$ entail that the following condition must hold:

$$
T^{\prime}=1+\frac{\alpha}{w} \frac{V_{3}}{V_{B}}
$$

Substituting (22) into (21) allow us to rewrite the expression for the marginal effective tax rate in a more convenient way:

$$
\tau^{\prime}=1+t_{3} \frac{\alpha}{w}+\frac{\alpha}{w}_{V_{B}}^{\mu} 1-t{\frac{V_{c}}{\partial B}}^{\text {१ }} .
$$

With this expression at hand, we can characterize the marginal effective tax rate in the following proposition.

Proposition 2 Under the assumption $\frac{\alpha^{L}}{w^{L}}<\frac{\alpha^{H}}{w^{H}}$, the constrained utilitarian optimum with redistribution from high- to low skilled agents is characterized by:

(a) a marginal effective tax rate faced by type 1 (low skilled, low taste for leisure) that is either positive or negative;

(b) a zero marginal effective tax rate faced by type 2 (high skilled, high taste for leisure) and type 3 (high skilled, low taste for leisure).

Proof. See Appendix $C$.

As anticipated, the results that we have obtained are rather standard. Since there is nobody longing for mimicking either one of the two types of high skilled agents (i.e. the corners intended for them are not L-linked to any other corner), the distortions brought about by income and commodity taxation will "average out" to zero so that they are "globally" undistorted at the margin, even though they are both affected by the horizontal equity constraint. Since, due to the assumption $\frac{\alpha^{L}}{w^{L}}<\frac{\alpha^{H}}{w^{H}}$, in this three-types economy, the high skilled, high taste for leisure agents will earn the lowest gross income while the high skilled, low taste for leisure agents will earn the highest one, the result parallels the "end-point" results on the desirability of zero marginal taxation at the top (so long as wages in the population are bounded above), and at the bottom (so long as everyone supplies some labour at the optimum, i.e. there is no bunching at zero hours, see Tuomala (1990)) of the skills distribution achieved in optimal tax literature dealing with a continuum of types. 
Note however that if we had instead made the assumption $\frac{\alpha^{H}}{w^{H}}<\frac{\alpha^{L}}{w^{L}}$, the METR faced by any of the types of high-skilled agents could differ from zero. The derivations in this slightly more complicated case are available upon request. It turns out that the METR of either type 2 or type 3 is zero, whereas the METR of the other type can be either positive or negative.

Regarding the low skilled agents, the METR could be of either sign. This is also not surprising since their corner is L-linked both to the one intended for the high skilled, high taste for leisure agents (by a binding upwards incentive compatibility constraint) and to the one intended for the high skilled, low taste for leisure ones (by a binding downwards incentive compatibility constraint); and while a binding upwards self-selection constraint calls for a negative METR in order to weaken the constraint, a binding downwards self-selection constraint calls for a positive METR to achieve the same goal.

\section{Concluding R emarks}

In this paper, we have not tried to make an ethical case for the horizontal equity principle. Indeed as argued by Kaplow (1995), although horizontal equity is intuitively appealing, there is need for studies that try both to justify this principle, and to derive a precise measure of equity from the justification. Our intentions have rather been to investigate how the preferred tax mix might change if we were to take horizontal equity seriously.

The investigation has made clear that the horizontal equity principle in combination with heterogeneity of preferences for leisure may seriously affect the incentives for income and commodity taxation. The basic intuition and policy implications from models with heterogeneity in ability only may not carry over into models where heterogeneity is two-dimensional. Contrary to normal findings, our results indicate that a good that is complementary to leisure need not be discouraged by the tax system, and a good that is normally expected to be discouraged by the tax system need not be taxed at a positive rate even if the economy is composed by only two private goods and leisure. As expected, the direction of redistribution is a crucial factor for the marginal effective tax rates, but the introduction of the horizontal equity restriction complicates matters here as well. It is for instance possible to have a marginal tax instead of a subsidy "on average" for the high ability, hard working-type even though the self-selection constraint relating them to the high ability, epicurean-type is binding upwards.

Before concluding, we note a possible objection against our assumptions discussed by Cuff (2000). In a model where the individuals are held responsible for their preferences, a higher taste for leisure can be interpreted as laziness. Another alternative is to interpret these preferences as some kind of disability. Whereas it is intuitive to argue that compensation for laziness should be ruled out, it is - at least in the framework of responsibility and 
compensation - less obvious that people that are for some other reason unable to work as hard as others, should not receive any compensation for this disability. Besides the benefits associated with a focus on one of the polar cases, our findings are also relevant as long as the taste for leisure among some individuals is to some extent interpreted more as laziness than as a disability.

To conclude, although our model is very simple and stylized, we hope that we have managed to call attention to the relevance and the potential consequences of a horizontal equity restriction for tax policy. Without doubt there are great prospects for more research in this relatively unexplored area of tax theory. 
Appendix A: Derivation of eq.

The first order conditions for $B^{1}, B^{2}$ and $B^{3}$ are as follows:

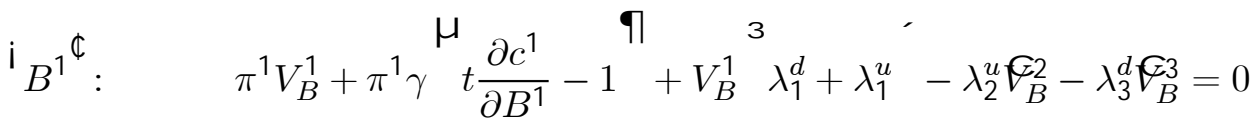

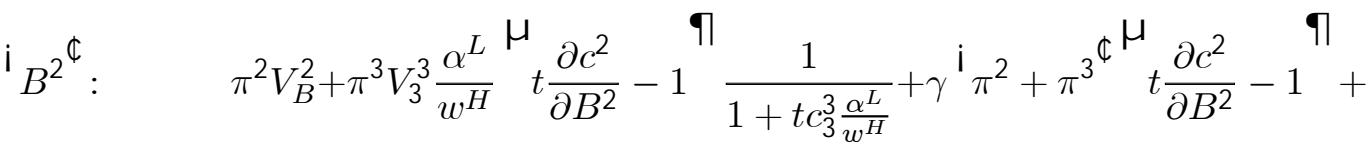

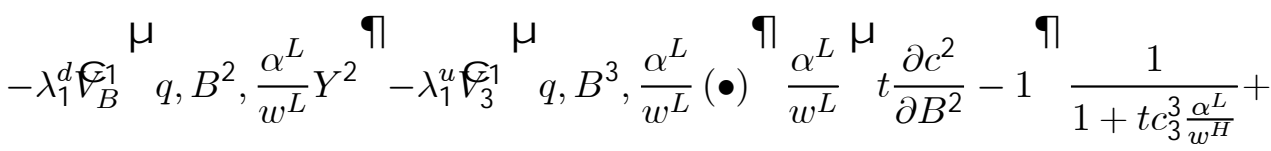

$$
\begin{aligned}
& +\lambda_{2}^{u} V_{B}^{2}+\lambda_{3}^{d} V_{3}^{3} \frac{\alpha^{L}}{w^{H}} t \frac{\partial c^{2}}{\partial B^{2}}-1 \frac{1}{1+t c_{3}^{3} \frac{\alpha^{L}}{w^{H}}}=0
\end{aligned}
$$

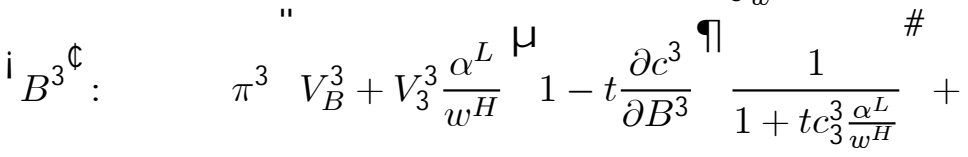

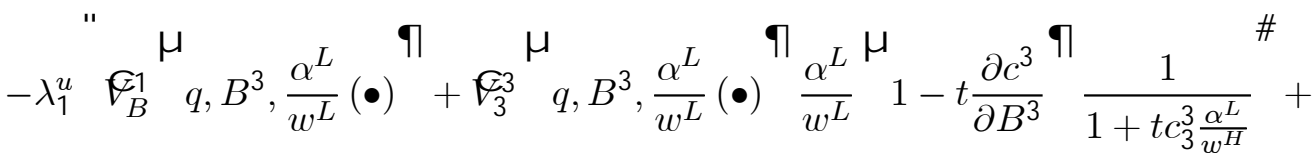

$$
+\lambda_{3}^{d} V_{B}^{3}+V_{3}^{3} \frac{\alpha^{L}}{w^{H}} 1-t{\frac{\partial c^{3}}{\partial B^{3}}}^{\text {ๆ }} \frac{1}{1+t c_{3}^{3} \frac{\alpha^{L}}{w^{H}}}=0
$$

Remembering that $\lambda_{1}^{u}=\lambda_{1}^{d}=0$ (Proposition 1 in Brito et al. (1990)), and applying Roy's identity, eq. (11), the first order condition for $t$, becomes:

$$
\begin{aligned}
& -\pi^{1} c^{1} V_{B}^{1}-\pi^{2} c^{2} V_{B}^{2}-\pi^{3} c^{3} V_{B}^{3}-\lambda_{2}^{u} c^{2} V_{B}^{2}-\lambda_{3}^{d} c^{3} V_{B}^{3}+\lambda_{2}^{u} c^{2} \theta_{B}^{2}+\lambda_{3}^{d} c^{b} G_{B}^{3}+ \\
& +\gamma \pi^{1} c^{1}+{ }^{\mathrm{i}} \pi^{2}+\pi^{3^{\natural}} c^{2}+t \frac{\partial c^{1}}{\partial q} \pi^{1}+\frac{\partial c^{2}}{\partial q} \pi^{2}+\pi^{3^{\boldsymbol{\phi}^{\natural}}}+ \\
& +\pi^{3}+\lambda_{3}^{d} V_{3}^{3} \frac{\alpha^{L}}{w^{H}} c^{2}-c^{3}+t^{\mu} \frac{\partial c^{2}}{\partial q}-\frac{\partial c^{3}}{\partial q} \quad \frac{1}{1+t c_{3}^{3} \frac{\alpha^{L}}{w^{H}}}=0 .
\end{aligned}
$$

From the first order conditions for $B^{1}, B^{2}$ and $B^{3}$, we have respectively: 


$$
\begin{aligned}
& -\pi^{1} V_{B}^{1}=\pi^{1} \gamma t \frac{\partial c^{1}}{\partial B^{1}}-1-\lambda_{2}^{u} \boldsymbol{G}_{B}^{2}-\lambda_{3}^{d} \boldsymbol{G}_{B}^{3}
\end{aligned}
$$

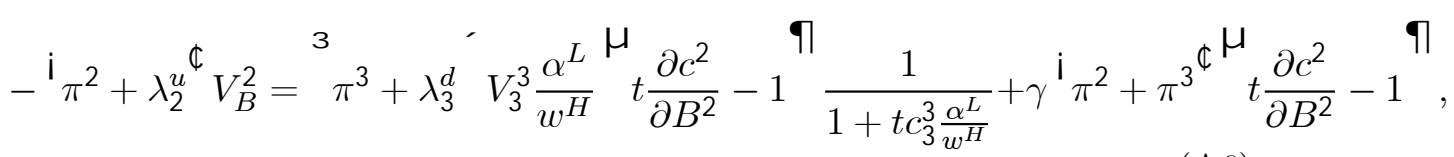

$$
\begin{aligned}
& -\pi^{3}+\lambda_{3}^{d} V_{B}^{3}=\pi^{3}+\lambda_{3}^{d} V_{3}^{3}{\frac{\alpha^{L}}{w^{H}}}^{\mu} 1-t{\frac{\partial c^{3}}{\partial B^{3}}}^{\text {ๆ }} \frac{1}{1+t c_{3}^{3} \frac{\alpha^{L}}{w^{H}}} .
\end{aligned}
$$

Substituting these expressions into eq. (A4), we get:

$$
\begin{aligned}
& \gamma \pi^{1} c^{1} t^{\mu} \frac{\partial c^{1}}{\partial B^{1}}-1-c^{1} \lambda_{2}^{u} \boldsymbol{G}_{B}^{2}-c^{1} \lambda_{3}^{d} G_{B}^{3}+\pi^{3} c^{2} V_{3}^{3} \frac{\alpha^{L}}{w^{H}} t \frac{\partial c^{2}}{\partial B^{2}}-1 \frac{1}{1+t c_{3}^{3} \frac{\alpha^{L}}{w^{H}}}+ \\
& +\gamma c^{2}{ }^{\mathbf{i}} \pi^{2}+\pi^{3} \boldsymbol{\phi}^{\mu} t \frac{\partial c^{2}}{\partial B^{2}}-1+\lambda_{3}^{d} c^{2} V_{3}{ }^{3} \frac{\alpha^{L}}{w^{H}} \quad t \frac{\partial c^{2}}{\partial B^{2}}-1 \frac{1}{1+t c_{3}{ }^{3} \frac{\alpha^{L}}{w^{H}}}+ \\
& +\pi^{3}+\lambda_{3}^{d} c^{3} V_{3}^{3} \frac{\alpha^{L}}{w^{H}} 1-t{\frac{\partial c^{3}}{\partial B^{3}}}^{\text {q }} \frac{1}{1+t c_{3}^{3} \frac{\alpha^{L}}{w^{H}}}+\lambda_{2}^{u} \mathrm{~b}^{2} G_{B}^{2}+\lambda_{3}^{d} \mathrm{~b}^{3} G_{B}^{3}+
\end{aligned}
$$

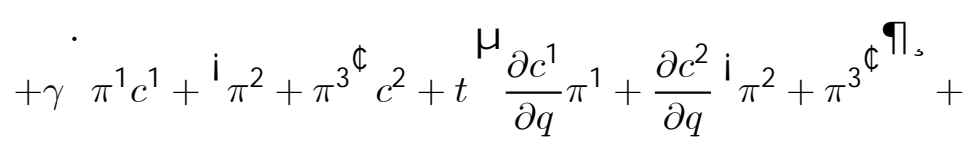

$$
\begin{aligned}
& +\pi^{3}+\lambda_{3}^{d} V_{3}^{3} \frac{\alpha^{L}}{w^{H}} c^{2}-c^{3}+t \frac{\partial c^{2}}{\partial q}-\frac{\partial c^{3}}{\partial q} \quad \frac{1}{1+t c_{3}^{3} \frac{\alpha^{L}}{w^{H}}}=0 .
\end{aligned}
$$

By using the Slutsky equation and by some further manipulation, one finally gets eq. (12). 


\section{Appendix B: Proof of Proposition 1}

From eq. (12), it follows that four main cases of commodity taxation can come true and each of them can be recognized as made up by an "ordinary" and a "non ordinary" sub-case. The four cases are summarized in the following table:

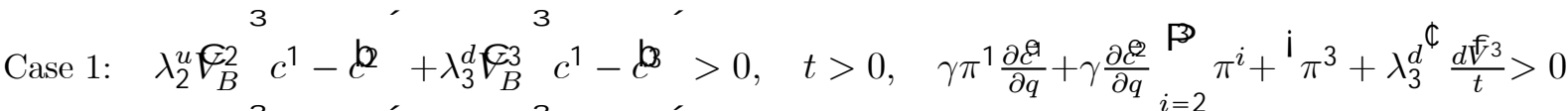

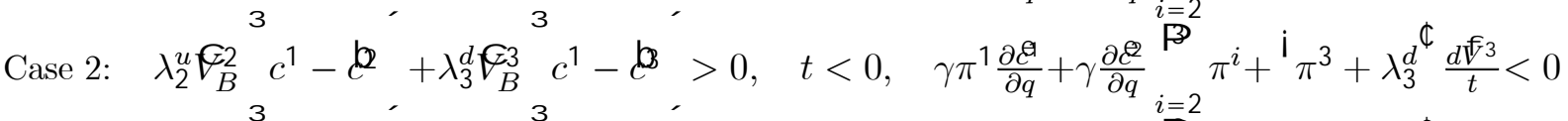

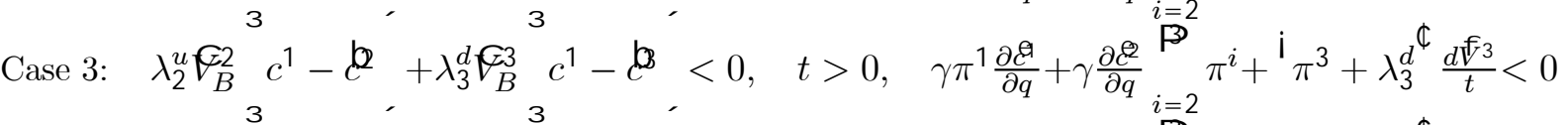

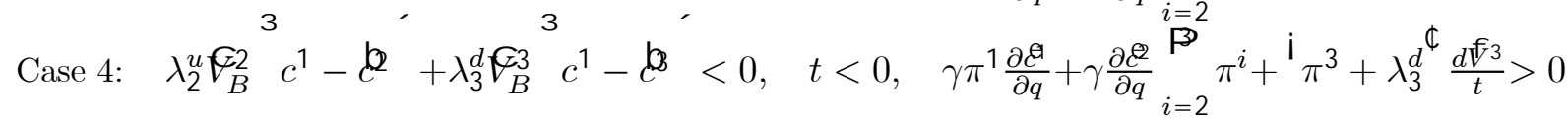

Note that both the first and the third case encompass a "non-ordinary" sub-case with a commodity complementary to labour but tax itive rate (respectively $c^{1}-c^{\mathbf{Q}}<0, c^{1}-c^{\mathbb{B}}>0$, with $\lambda_{2}^{u} G_{B 3_{3}}^{2} c^{1}-c^{\mathbf{Q}}$, + $\lambda_{3}^{d} G_{B}^{3} c^{1}-c^{\mathbf{B}},>0$, and $c^{1}-c^{\mathbf{Q}}<0, c^{1}-c^{\mathbf{B}}>0$, with $\lambda_{2}^{u} G_{B}^{2} c^{1}-c^{\mathbf{Q}}+$ $\left.\lambda_{3}^{d} G_{B}^{3} c^{1}-c^{b}<0\right)$, besides the standard case of a commodity complementary to leisure and baxed at’a positive rate (respectively $c^{1}-c^{\mathbb{Q}}>0$, $c^{1}-c^{\mathrm{B}}<0$, with $\lambda_{2}^{u} G_{B_{3}}^{2} c^{1}-c^{2},+\lambda_{3}^{d} G_{B_{3}}^{3} c^{1}-c_{,},>0$, and $c^{1}-c^{\mathbb{Q}}>0$, $c^{1}-c^{8}<0$, with $\left.\lambda_{2}^{u} G_{B}^{2} c^{1}-c^{2}+\lambda_{3}^{d} \bigoplus_{B}^{3} c^{1}-c^{b}<0\right)$.

The second and the fourth case on the other hand both encompass a "non-ordinary" sub-case of a commodity complementary to leisure but in spise of this subsidized (respectively $c^{1}-c^{\mathfrak{2}}>0, c^{1}-c^{\mathbb{B}}<0$, with $\lambda_{2}^{u} G_{B}^{2} c^{1}-c^{\mathbf{Q}},+\lambda_{3}^{d} G_{B}^{3} c^{1}-c^{\mathbb{B}},>0$, and $c^{1}-c^{\mathbf{Q}}>0, c^{1}-c^{\mathbb{B}}<0$, with $\left.\lambda_{2}^{u} G_{B}^{2} c^{1}-c^{\mathbf{Q}}+\lambda_{3}^{d} G_{B}^{3} \quad c^{1}-c^{b}<0\right)$, besides a standard one of a commodity complementary to labour and subsidized (respectively $c^{1}-c^{\mathbf{Q}}<0$, $c^{1}-c^{\mathrm{B}}>0$, with $\lambda_{2}^{u} G_{B_{3}}^{2} c^{1}-c^{2}, \lambda_{3}^{d} G_{B}^{3} c^{1}-c_{,}^{\mathbf{B}}>0$, and $c^{1}-c^{\mathbf{Q}}<0$, $c^{1}-c^{\mathbb{B}}>0$, with $\left.\lambda_{2}^{u} G_{B}^{2} \quad c^{1}-c^{2}+\lambda_{3}^{d} G_{B}^{3} \quad c^{1}-c^{B}<0\right)$.

For (a), note that the mentioned "non-ordinary" sub-cases in case 2 and case 3 differ from the standard policy prescription because the sign of the right-hand side of eq. (12) is not determined by the relation of the taxed commodity with labor/leisure. Thus, it is possible that a good that is normally expected to be discouraged (encouraged) in order to loosen the self-selection constraints, should actually be encouraged (discouraged) in a model where the agents differ along more than one dimension. 
For (b), note that the only "non-ordinary" sub-cases that can be regarded as truly "anomalous" are those belonging to the first and fourth rows of the table, since they are respectively concerned with a commodity complementary to labour, the consumption of which, according to the sign of the right-hand side of eq. (12), should be encouraged, and with a commodity complementary to leisure, the consumption of which, always according to the sign of the right-hand side of eq. (12), should be discouraged. If we consider in more detail those two truly "anomalous" sub-cases, we find that they share the feature of being characterized by a high and positive value of the ratio $\frac{d^{\mathbb{f}} 3}{t}$, high enough to be able to outweigh the absolute value of $\gamma \pi^{1} \frac{\partial \varepsilon^{\mathcal{Q}}}{\partial q}+\gamma{\frac{\partial \mathcal{\varepsilon}^{\mathcal{Q}}}{\partial q}}_{i=2}^{\mathrm{PB}} \pi^{i}$, and reverse the sign of the term by which $t$ is multiplied in the left-hand side of eq. (12). However, whilst in the former sub-case this means a high and positive value of $d f^{3}$ (since we are looking for conditions that are compatible with $t>0$ ), in the latter sub-case this requirement means a high and negative value of the aforesaid term (since we are looking for conditions that are compatible-with a subsidy). Apart from this difference, from eq. (17) we get that $\frac{-\partial^{\mathbb{e}}}{\partial q}>{\frac{-\partial \mathcal{E}^{-}}{\partial q}}^{-}$must be satisfied in both of those sub-cases.

$¥$ 


\section{Appendix C: Proof of Proposition 2}

Considering the "normal" case when redistribution is directed towards the low skilled agents and $\lambda_{2}^{u}=\lambda_{1}^{d}=0$, the first order conditions of the planner's problem with respect to the gross incomes $Y^{1}$ and $Y^{2}$ are as follows:

$$
\begin{gathered}
\left(Y^{1}\right): \quad \pi^{1} V_{3}^{1} \frac{\alpha^{L}}{w^{L}}=\lambda_{2}^{u} \mathfrak{G}_{3}^{2} \frac{\alpha^{H}}{w^{H}}+\lambda_{3}^{d} \mathfrak{G}_{3}^{3} \frac{\alpha^{L}}{w^{H}}-\pi^{1} \gamma^{\mu} 1+t c_{3}^{1} \frac{\alpha^{L}}{w^{L}},(\mathrm{q} 1) \\
\left(Y^{2}\right): \pi^{2} V_{3}^{2} \frac{\alpha^{H}}{w^{H}}+\pi^{3} V_{3}^{3} \frac{\alpha^{L}}{w^{H}} \frac{d Y^{3}}{d Y^{2}}+\gamma^{\mathrm{i}} \pi^{2}+\pi^{3^{4}}{ }^{\mu} 1+t c_{3}^{2} \frac{\alpha^{H}}{w^{H}}+\lambda_{2}^{u} V_{3}^{2} \frac{\alpha^{H}}{w^{H}}+\lambda_{3}^{d} V_{3}^{3} \frac{\alpha^{L}}{w^{H}} \frac{d Y^{3}}{d Y^{2}}=0 .
\end{gathered}
$$

Making use of eq. (9), eq. (C2) becomes:

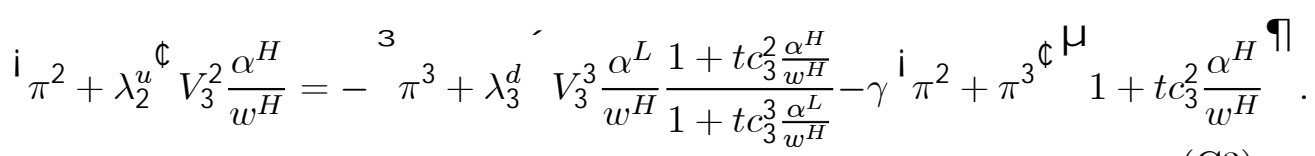

For (a), divide (C1) by (A5) and multiply the result by $\pi^{1} \gamma \quad t \frac{\partial c^{1}}{\partial B^{1}}-1-$ $\lambda_{2}^{u} \Theta_{B}^{2}-\lambda_{1}^{d} \Theta_{B}^{3}$, which gives

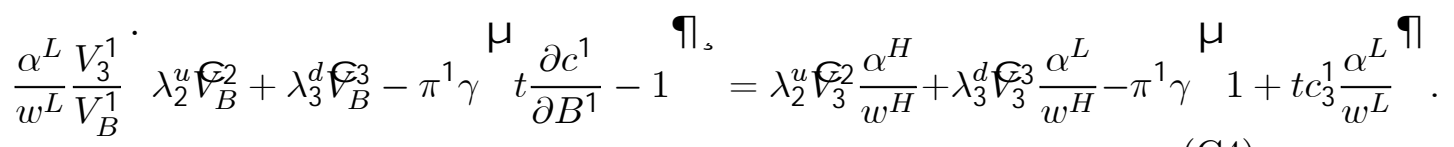

This expression simplifies to

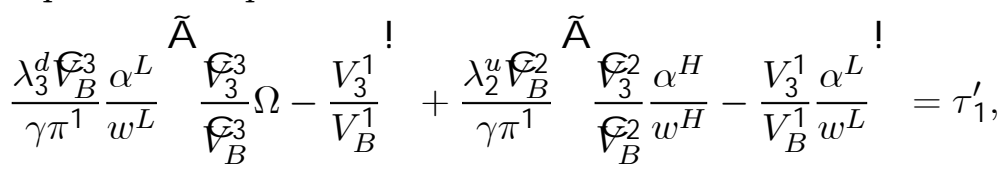

where $\Omega=\frac{w^{L}}{w^{H}}$. Introducing the notation $\overline{w^{1}}=\frac{w^{L}}{\alpha^{L}}, \overline{w^{2}}=\frac{w^{H}}{\alpha^{H}}$, and $\overline{w^{3}}=\frac{w^{H}}{\alpha^{L}}$, eq. (C5) can be written

$$
\frac{1}{\overline{w^{1}}} \frac{\lambda_{3}^{d} G_{B}^{3}}{\gamma \pi^{1}} \frac{\tilde{A}}{G_{3}^{3}} \Omega-\frac{V_{3}^{1}}{V_{B}^{1}}+\frac{\lambda_{2}^{u} G_{B}^{2}}{\gamma \pi^{1}} \frac{\tilde{A}}{G_{3}^{2}} \overline{\Omega^{1,2}}-\frac{V_{3}^{1}}{V_{B}^{1}}=\tau_{1}^{\prime},
$$

where $\overline{\Omega^{1,2}}=\frac{\overline{w^{1}}}{w^{2}}$. In eq. (C6) we have that $\frac{G_{3}^{3}}{G_{B}^{3}} \Omega-\frac{V_{3}^{1}}{V_{B}^{1}}>0$ since agents of type 1 have indifference curves in $(Y, B)$-space that are at every point steeper than the ones of agents of type 3 , and $\Omega<1$. On the other hand $\frac{\mathcal{G}_{3}^{2}}{\mathcal{G}_{B}^{2}} \overline{\Omega^{1,2}}-\frac{V_{3}^{1}}{V_{B}^{1}}<0$ because, under assumption 1, agents of type 2 have indifference curves in the same space that are at every point steeper than the ones of agents of 
type 1 , and $\overline{\Omega^{1,2}}>1$. Since $\overline{w^{1}}$ and the ratios $\frac{\lambda_{3}^{d} \mathscr{G}_{B}^{3}}{\gamma \pi^{1}}$ and $\frac{\lambda_{2}^{u} \mathscr{G}_{B}^{2}}{\gamma \pi^{1}}$ are all positive, the sign of the METR faced by type 1 is ambiguous.

For part (b), we start with sype 2. Dividing (C3) by (A6) and multiplying the result by $\pi^{3}+\lambda_{3}^{d} V_{3}^{3} \frac{\alpha^{L}}{w^{H}} \quad t \frac{\partial c^{2}}{\partial B^{2}}-1 \frac{1}{1+t c_{3}^{3} \frac{\alpha^{L}}{w^{H}}}+\gamma^{i} \pi^{2}+\pi^{3^{4}} t \frac{\partial c^{2}}{\partial B^{2}}-1$ gives

$$
\begin{aligned}
& \frac{\alpha^{H}}{w^{H}} \frac{V_{3}^{2}}{V_{B}^{2}}-\pi^{3}+\lambda_{3}^{d} V_{3}^{3} \frac{\alpha^{L}}{w^{H}} \frac{t \frac{\partial c^{2}}{\partial B^{2}}-1}{1+t c_{3}^{3} \frac{\alpha^{L}}{w^{H}}}-\gamma^{\mathrm{i}} \pi^{2}+\pi^{3}{ }^{\mu} t \frac{\partial c^{2}}{\partial B^{2}}-1 \\
= & -\pi^{3}+\lambda_{3}^{d} V_{3}^{3} \frac{\alpha^{L}}{w^{H}} \frac{1+t c_{3}^{2} \frac{\alpha^{H}}{w^{H}}}{1+t c_{3}^{3} \frac{\alpha^{L}}{w^{H}}}-\gamma^{\mathrm{i}} \pi^{2}+\pi^{{ }^{3}}{ }^{\mu} 1+t c_{3}^{2} \frac{\alpha^{H}}{w^{H}} .
\end{aligned}
$$

This simplifies to

$$
\frac{\alpha^{H}}{w^{H}} \frac{V_{3}^{2}}{V_{B}^{2}} 1-t{\frac{\partial c^{2}}{\partial B^{2}}}^{\text {ๆ }}=-1-t c_{3}^{2} \frac{\alpha^{H}}{w^{H}} \Longrightarrow \tau_{2}^{\prime}=0
$$

where in the last passage we made use of (23).

For type 3, we use eq. (A7) stating that

$$
-V_{B}^{3}=V_{3}^{3}{\frac{\alpha^{L}}{w^{H}}}^{\mu} 1-t{\frac{\partial c^{3}}{\partial B^{3}}}^{\text {ๆ }} \frac{1}{1+t c_{3}^{3} \frac{\alpha^{L} w^{H}}{w^{\prime}}},
$$

which can be rewritten as

$$
{\frac{V_{3}^{3}}{V_{B}^{3}}{\frac{\alpha}{w^{H}}}^{\mu}}^{\mu} 1-t{\frac{\partial c^{3}}{\partial B^{3}}}^{\text {ๆ }} \frac{1}{1+t c_{3}^{3} \frac{\alpha^{L}}{w^{H}}}+1=0 .
$$

Finally, multiplying by $1+t c_{3}^{3} \frac{\alpha^{L}}{w^{H}}$ gives

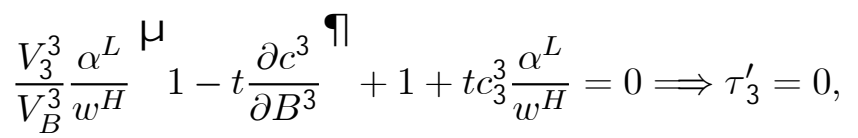

where in the last passage we again made use of (23).

$¥$ 


\section{References}

Atkinson, A. B., and J. E. Stiglitz (1976), "The Design of Tax Structure: Direct versus Indirect Taxation," Journal of Public Economics 6, 55-75.

Atkinson, A. B., and J. E. Stiglitz (1980), Lectures on Public Economics, New York: McGraw-Hill.

Auerbach, A. J., and K. A. Hassett (1999), "A New Measure of Horizontal Equity," NBER Working Paper 7035.

Balcer, Y., and E. Sadka (1986), "Equivalence Scales, Horizontal Equity and Optimal Taxation under Utilitarianism," Journal of Public Economics 29, 79-97.

Balestrino, A., A. Cigno, and A. Pettini (1999), "Doing Wonders with an Egg: Direct and Indirect Taxation when Households Differ in Market and Non-market Abilities," CESifo Working Paper 181.

Berliant, M. C., and R. P. Strauss (1985), "The Horizontal and Vertical Equity Characteristics of the Federal Individual Income Tax, 1966-1977," in Martin, D., and T. Smeeding (eds.), Horizontal Equity, Uncertainty, and Economic Well-being. NBER Studies in Income and Wealth, vol. 50. Chicago: University of Chicago Press.

Besley, T., and S. Coate (1995), "The Design of Income Maintenance Programmes," Review of Economic Studies 62, 187-221.

Boadway, R. et al. (2002), "Optimal Redistribution with Heterogeneous Preferences for Leisure," forthcoming in Journal of Public Economic Theory.

Bossert W. (1995), "Redistribution Mechanisms Based on Individual Characteristics," Mathematical Social Sciences, 29, 1-17.

Brito, D. L. et al. (1990), "Pareto Efficient Tax Structures," Oxford Economic Papers 42 (1), 61-77.

Cremer, H., P. Pestieau, and J. C. Rochet (2001) "Direct Versus Indirect Taxation: the Design of the Tax Structure Revisited," International Economic Review 42, 781-799.

Cuff, K. (2000), "Optimality of Workfare with Heterogeneous Preferences," Canadian Journal of Economics 33, 149-174.

Ebert, U., (1988). "Optimal Income Taxation: On the Case of Two-dimensional Populations," Discussion Paper A-169, University of Bonn.

Feldstein, M. (1976), "On the Theory of Tax Reform," Journal of Public Economics 6, 77-104. 
Fleurbaey, M., and F. Maniquet (1999), "Compensation and Responsibility," forthcoming in K. J. Arrow, A. K. Sen and K. Suzumura (eds.), Handbook of Social Choice and Welfare.

Guesnerie, R., and J. Seade (1982), "Nonlinear Pricing in a Finite Economy," Journal of Public Economics 17, 157-179.

Johnson, S. B. and T. Mayer (1962), "An Extension of Sidgewick's Equity Principle," Quarterly Journal of Economics 76, 454-463.

Kaplow, L. (1989), "Horizontal Equity: Measures in Search of a Principle," National Tax Journal 42, 139-154.

Kaplow, L. (1995), "A Fundamental Objection to Tax Equity Norms: A Call for Utilitarianism," National Tax Journal 48, 497-514.

Kaplow, L. (2000), "Horizontal Equity: New Measures, Unclear Principles," NBER Working Paper 7649.

Kaplow, L. and S. Shavell (2000), "Notions of Fairness versus the Pareto Principle: On the Role of Logical Consistency," Yale Law Journal 110, 237-249.

Kaplow, L. and S. Shavell (2001a), "Fairness versus Welfare," Harvard Law Review 114, 966-1388.

Kaplow, L. and S. Shavell (2001b), "Any Non-welfarist Method of Policy Assessment Violates the Pareto Principle," Journal of Political Economy 109, 281-286.

King, M. A. (1983), "An Index of Inequality: With Applications to Horizontal Equity and Social Mobility," Econometrica 51, 99 115 .

Mirrlees, J. (1976), "Optimal Tax Theory: a Synthesis," Journal of Public Economics 6, 327-358.

Musgrave, R. A. (1959), The Theory of Public Finance, New York: McGraw-Hill.

Nozick, R. (1974), Anarchy, State, and Utopia, Oxford: Blackwell.

Plotnick, R. (1981), "A Measure of Horizontal Equity," Review of Economics and Statistics 63, 283-288.

Pollack, R. A. (1969), "Conditional Demand Functions and Consumption Theory," Quarterly Journal of Economics 83 (1), 6078.

Rosen, H. S. (1978), "An Approach to the Study of Income, Utility and Horizontal Equity," Quarterly Journal of Economics 92, 307-322. 
Sandmo, A. (1993), "Optimal Redistribution when Tastes Differ," Finanzarchiv 50, 149-163.

Stiglitz, J. E. (1982), "Utilitarianism and Horizontal Equity: The Case for Random Taxation," Journal of Public Economics 18, 133.

Tarkiainen, R. and M. Tuomala (1999), "Optimal Nonlinear Income Taxation with a Two-Dimensional Population; A Computational Approach," Computational Economics 13, 1-16.

Tuomala, M. (1990), Optimal Income Tax and Redistribution, Oxford: Clarendon Press.

Westen, P. (1982), "The Empty Idea of Equality," Harvard Law Review 95, 537-596.

Weymark, J. A. (1986), "A Reduced-Form Optimal Nonlinear Income Tax Problem," Journal of Public Economics 30, 199 217. 